IP Periodica Polytechnica Civil Engineering

60(4), pp. 561 572, 2016

DOI: $10.3311 /$ PPci.8551

Creative Commons Attribution (1)

RESEARCH ARTICLE

\section{Bearing Capacities of the Structure and Joint of JUNO Central Detector}

\author{
Zongyi Wang, Yuangqing Wang, Yuekun Heng, Xinxi Du, Zhonghua Qin
}

Received 11-09-2015, revised 16-12-2015, accepted 17-12-2015

\begin{abstract}
The Jiangmen Underground Neutrino Observatory (JUNO) central detector will be placed underground to detect neutrinos. In order to achieve the feasible scheme for JUNO, the structural scheme of an acrylic ball supported by a double-layer stainless steel latticed shell is designed and modeled using ABAQUS software. The bearing capacity of the structure under working condition is investigated and influences of external factors are analyzed. For the purpose of studying the load-bearing behavior of the joint of acrylic and stainless steel in this scheme, tests of three joint specimens are conducted and the results are compared with finite element (FE) predictions. It is concluded that the structure is safe and reliable under the effects of external factors. The bearing capacity of the joint is at least 2 times as large as the design load and the stress on the acrylic is limited within $10 \mathrm{MPa}$.
\end{abstract}

\section{Keywords}

Neutrino detector $\cdot$ structural scheme $\cdot$ acrylic $\cdot$ stainless steel $\cdot$ joint $\cdot$ bearing capacity

\section{Zongyi Wang}

Wuhan University, School of Civil Engineering, Wuhan 430072, China e-mail: wangzongyi1990@126.com

\section{Yuangqing Wang}

Tsinghua University, Key Laboratory of Civil Engineering Safety and Durability of Education Ministry, Beijing 100084, China

e-mail: wang-yq@mail.tsinghua.edu.cn

\section{Yuekun Heng}

Institute of High Energy Physics, Chinese Academy of Sciences, 100049, Beijing, China

e-mail: hengyk@ihep.ac.cn

\section{Xinxi Du}

Wuhan University, School of Civil Engineering, Wuhan 430072, China e-mail: duxinxi@163.com

\section{Zhonghua Qin}

Institute of High Energy Physics, Chinese Academy of Sciences, Beijing 100049, China

e-mail: qinzh@ihep.ac.cn

\section{Introduction}

Since Wolfgang E. Pauli, the Austrian physicist, firstly predicted the existence of neutrinos, scientists from all over the world started to investigate neutrinos. As the basis of neutrino experiments, the neutrino detector was also intensively investigated by scholars. Numerous kinds of neutrino detectors have been established worldwide and they can roughly be classified into four types in structure: cylindrical structure [1], acrylic spherical structure [2], balloon (thin membrane) structure [3] and linetype structure [4,5]. For the detectors with the structure of acrylic sphere, the SNO detector [2] is the most typical one, which is located at $2039 \mathrm{~m}$ underground and has the diameter of $12 \mathrm{~m}$ and the ability to contain 1 kilotons of detecting liquid. Arthur B. McDonald, the chief scientist of SNO neutrino experiment successfully won the 2015 Noble Prize in Physics. The JUNO central detector will adopt the acrylic spherical structure as well and be supported by a stainless steel latticed shell. Its diameter will be $35.5 \mathrm{~m}$ and the capacity will reach 20 kilotons. In view of the huge scale, the bearing capacity of the structure is of high requirement. In the working condition, the maximum Mises stress of large areas on the acrylic can not exceed $5 \mathrm{MPa}$ and that of local parts should be limited within $10 \mathrm{MPa}$ [6]. Moreover, the structure must be safe and reliable under the effects of external factors.

Besides, the connecting joint of the acrylic and stainless steel is the key studying issue, since it directly relates to the safety of the whole structure. Researches about the acrylic (polymethyl methacrylate, PMMA) and stainless steel have been carried out in depth by many scholars. Among them, Wu et al. [7] compared test results of PMMA under the tensile loading at intermediate strain rates $\left(2.92 \times 10^{-1}, 6.54 \times 10^{-1}, 2.81,18.6 \mathrm{~s}^{-1}\right)$ with those under quasi-static loading $\left(2.31 \times 10^{-5}, 2.38 \times 10^{-4}, 2.38 \times 10^{-3}, 2.00 \times 10^{-2} \mathrm{~s}^{-1}\right)$. They reported that the mechanical behavior of PMMA was strongly sensitive to the strain rate. The strength and initial modulus increased simultaneously with the strain rate, while the fracture strain exhibited the opposite tendency. Richeton et al. [8, 10] conducted the uniaxial compressive experiment on PMMA under the temperature ranging from $-40^{\circ} \mathrm{C}$ to $180^{\circ} \mathrm{C}$ and strain 
rate from $0.0001 \mathrm{~s}^{-1}$ to $5000 \mathrm{~s}^{-1}$. The result showed that the mechanical response was noticeably affected by the temperature and the strain rate. The increase of temperature or decrease of strain rate would lead to the decrease of the initial Young's modulus, yield stress and strain hardening rate of PMMA. Chen et al. [11] also experimentally studied the tensile and compressive behavior of PMMA under dynamic and quasi-static loading. They concluded that the dynamic stress-strain behavior showed a great discrepancy under tension and compression, while the difference was less significant in the quasi-static test. Specimens failed in a ductile form under the quasi-static tension, but in a brittle form under the dynamic tension. Palm et al. [12] investigated the large strain mechanical behavior of PMMA near the glass transition temperature and found a three-dimensional constitutive model which was capable of describing the stress-strain behavior successfully. Hassan et al. [13, 14] studied the influence of annealing temperature on the dynamic crack propagation in PMMA and revealed that annealing under $90^{\circ} \mathrm{C}$ was recommended for the casted type PMMA and $85^{\circ} \mathrm{C}$ for the extruded type with the intent of obtaining the maximum dynamic stress intensity factor, $\mathrm{K}_{D}$.

With respect to the stainless steel, Wang et al. [15,-19] carried out substantial researches. In literature [15], bearing capacities of the stainless steel X-type, H-type and I-type spiders used in point supported glass facades were experimentally and numerically investigated, and a proper design formula was proposed for the stainless steel spiders. Fan et al. [20,21] studied the nonlinear stress-strain behavior, anisotropy and cold hardening properties of stainless steel materials through mechanical property tests and conducted stub column tests to investigate the failure phenomenon, process and mechanism of stainless steel stub columns withstood axial and eccentric load. Salih et al. [22, 24] performed a numerical research on the bearing capacity of stainless steel connections between both thick and thin plates, and the FE predicted results were validated by the test results. The previous studies mainly focused on the respective mechanical behaviors of acrylic (PMMA) and stainless steel, however, little attention was paid to the bearing capacity of the connection of acrylic and stainless steel.

In the present paper, the structural scheme of an acrylic ball supported by a double-layer stainless steel latticed shell is firstly proposed, and the FE model of the whole structure is subsequently established in ABAQUS software. The bearing capacity of the structure under the working condition is studied and influences of the external factors are analyzed. As for the joint of acrylic and stainless steel, three specimens are designed and tested, and the corresponding FE simulations are carried out.

\section{Design and FE model of the structure}

\subsection{Structural design}

The JUNO central detector will be installed in a large water tank. The density of the liquid scintillator inside the acrylic ball is $0.866 \times 10^{3} \mathrm{~kg} / \mathrm{m}^{3}$ and that of water outside is $10^{3} \mathrm{~kg} / \mathrm{m}^{3}$. Due to the density difference of these two liquids, a kind of upward buoyancy will be produced in the working condition. Meanwhile, 15000 photomultipliers (PMTs) will be mounted on the stainless steel latticed shell in order to capture the light produced inside the acrylic ball. The diameter of the PMT is $0.5 \mathrm{~m}$ and mass $10 \mathrm{Kg}$.

For the purpose of obtaining a structural scheme satisfying the fundamental requirement, the scheme of an acrylic ball supported by a double-layer stainless steel latticed shell is proposed, as shown in Fig. 1. a). The diameter of the acrylic ball is $35.5 \mathrm{~m}$, the thickness of the upper hemisphere is set to be $80 \mathrm{~mm}$ and that of the lower hemisphere is determined as $120 \mathrm{~mm}$. For the stainless steel latticed shell, the diameter of the inner layer is $38.5 \mathrm{~m}$ and that of the outer layer is $40.5 \mathrm{~m}$. Web members are utilized to connect the inner and outer layer, whilst the detector is fixed on the ground by bearing supports. The acrylic ball and stainless steel latticed shell are linked up by some stainless steel braces. The patched acrylic and fastener are utilized in this connection to enlarge the contacting area, as presented in Fig. 1. b). Each joint between stainless steel components on the inner layer corresponds to a stainless steel brace which is connected with the acrylic ball. However, only joints on the lower hemisphere of the outer layer correspond to braces, since the pressure difference on the lower hemisphere is significantly higher than that on the upper hemisphere and more braces on the lower is beneficial for the even stress distribution. Eventually, the total number of braces is 503. The circle tube is adopted for all the stainless steel components and the sizes are shown in Table 1

\subsection{FE model and analysis}

The geometric model is firstly established in AUTOCAD software, and afterwards put into the Rhinoceros software to generate the file with the extension of "igs", which can be read in ABQAQUS package. In the FE model, the stainless steel components are simulated by the element B31. B31 is a 2 node linear beam element with one integration point. For the acrylic ball, element S4R and S3 are adopted. S4R is the 4-node general-purpose shell element with reduced integration and S3 refers to the 3-node triangular shell element, which is degenerated version of S4R and fully compatible with S4R [25, 26]. Both the elements S4R and S3 have just one integration point. The large area of the acrylic ball is stimulated by the element S4R, however, the element S3 is utilized for some parts with uneven mesh generation. The thickness integration follows Simpson rule and the number of thickness integration points is 5 . Eventually, the total numbers of element B31, S4R and S3 are 30829, 14411 and 280, respectively, and the node number is 42648. The connections between the stainless steel components are rigid, while the rotation freedoms of braces (apart from some braces near the poles) are released. In order to improve the calculating efficiency, braces are linked up with the acrylic ball directly and the real joint in Fig. 1 (b) is not taken into consideration in the whole FE model. Since the acrylic and stainless steel 
Tab. 1. Sizes of stainless steel components

\begin{tabular}{cccccc}
\hline Location & $\begin{array}{c}\text { Brace between } \\
\text { acrylic and } \\
\text { latticed shell }\end{array}$ & $\begin{array}{c}\text { Inner layer } \\
\text { latticed shell }\end{array}$ & $\begin{array}{c}\text { Outer layer } \\
\text { latticed shell }\end{array}$ & $\begin{array}{c}\text { Web member of } \\
\text { latticed shell }\end{array}$ & $\begin{array}{c}\text { Bearing } \\
\text { support }\end{array}$ \\
\hline Size $(\mathrm{mm})$ & $\Phi 102 \times 12$ & $\Phi 273 \times 8$ & $\Phi 273 \times 8$ & $\Phi 219 \times 8$ & $\Phi 400 \times 20$ \\
\hline
\end{tabular}

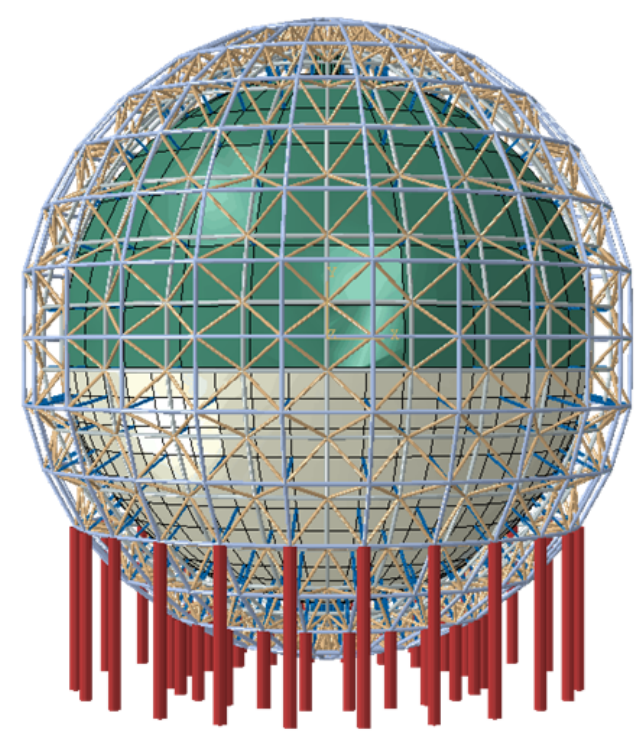

(a)

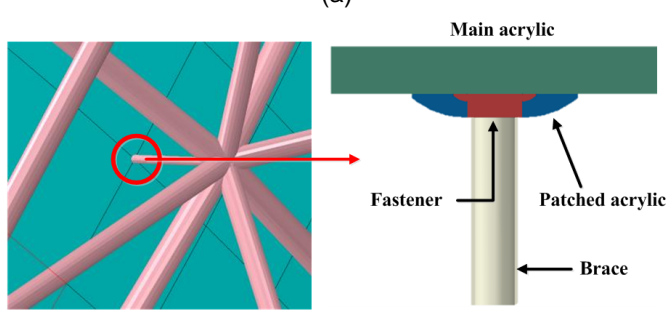

(b)

Fig. 1. (a) Structural scheme, (b) connecting joint of acrylic and stainless steel

are in the state of low-stress level in the working condition and the materials still keep elastic, the linear elastic behavior merely requires to be considered. The mechanical properties of materials are listed in Table 2. As for loads applied in the model, three kinds of load are taken into account: structural self-weight, selfweight and buoyancy of PMTs, the pressure difference inside and outside the acrylic ball. Inasmuch as the PMTs are mounted on the inner layer latticed shell, their self-weight and buoyancy are applied on the inner layer in the form of point load. Furthermore, the pressure difference on the acrylic ball is able to be simulated by the linearly distributed pressure in ABAQUS. Besides, the partial load factor, 1.35 , is taken for all the loads.

The predicted results are shown in Fig. 2. It is noticed that the maximum Mises stress on the acrylic ball is $8.5 \mathrm{MPa}$, located at the lower hemisphere and smaller than $10 \mathrm{MPa}$. The maximum Mises stress on the latticed shell is $83.4 \mathrm{MPa}$, significantly lower than the yield strength. The maximum axial force of braces is equal to $193.6 \mathrm{KN}$ and it is tensile force. Moreover, the maximum structural deflection is about $35.1 \mathrm{~mm}$, approximately equal to $1 / 1014$ of the span which meets the design criteria of Chinese space frame structures code, JGJ7-2010 [29].

\section{Influence factor analysis}

The working life of the JUNO central detector is 20 years. Therefore, three influence factors which may occur in this period are taken into consideration: the variation of the liquid level, earthquake action and joint failure.

\subsection{Variation of the liquid level}

Water is outside the acrylic ball and the level is determined. However, the liquid level of the scintillator inside the acrylic ball can be artificially adjusted. In the normal working condition, the liquid levels are the same. Nevertheless, with the intent of studying the influence of liquid-level variation on the bearing capacity of the structure, the liquid-level difference inside and outside the acrylic ball is taken as $-2 \mathrm{~m},-1 \mathrm{~m}, 0 \mathrm{~m}, 1 \mathrm{~m}, 2 \mathrm{~m}$, respectively. The calculating results are summarized in Table 3 .

It is noticed that the maximum Mises stress on the acrylic and latticed shell and the maximum forces of braces decrease with the increase of liquid-level difference. When the difference is $2 \mathrm{~m}$, the maximum Mises stress on the acrylic is equal to $7.0 \mathrm{MPa}$ and decreased by $17.2 \%$ compared with the results at $0 \mathrm{~m}$. On the contrary, the maximum stress reaches $12.1 \mathrm{MPa}$ when the difference is $-2 \mathrm{~m}$. However, if the partial load factor, 1.35 , is not taken into account, the real stress is equal to 9.0 MPa and still lower than $10 \mathrm{MPa}$. The maximum structural deflection at $2 \mathrm{~m}$ is higher than that at $0 \mathrm{~m}$, while it is still very small compared to the span and therefore not the controlling factor. Accordingly, a proper elevation of the liquid level inside is advantageous for the structure.

\subsection{Earthquake action}

Based on the Chinese code for seismic design of buildings, GB50011-2010 [30], the seismic precautionary intensity of Jiangmen city is 7 degree and the design basic acceleration of ground motion is $0.1 \mathrm{~g}$. The experimental site of the JUNO central detector follows these items. Moreover, this detector is installed at $700 \mathrm{~m}$ underground and will be less affected by the earthquake relative to the structures above the ground [31-33]. Consequently, the adption of the design basic acceleration of the ground motion as $0.1 \mathrm{~g}$ for the JUNO central detector is very conservative.

The results under earthquake action are listed in Table 4. It is known that the maximum Mises stress on the acrylic is equal 
Tab. 2. Mechanical properties of materials

\begin{tabular}{ccccc}
\hline Material & Density $\left(\mathrm{Kg} / \mathrm{m}^{3}\right)$ & $\begin{array}{c}\text { Young's modulus } \\
(\mathrm{GPa})\end{array}$ & $\begin{array}{c}\text { Yield strength } \\
(\mathrm{MPa})\end{array}$ & Poisson ratio \\
\hline $\begin{array}{c}\text { Stainless steel } \\
\text { (Austenite 316) 27 }\end{array}$ & 8000 & 200 & 240 & 0.3 \\
\hline Acrylic 28. & 1180 & 2.77 & 50 & 0.376 \\
\hline
\end{tabular}

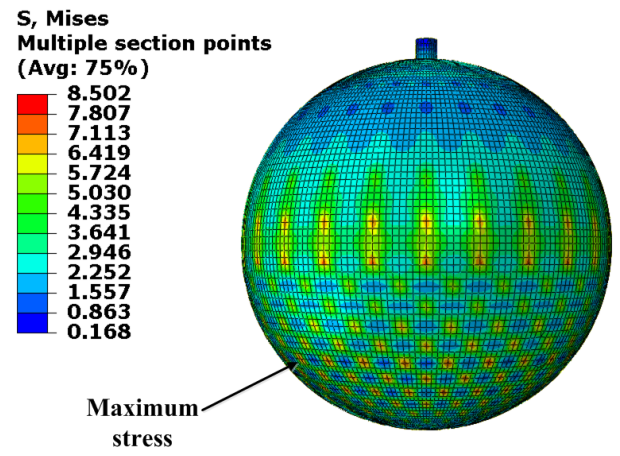

(a)

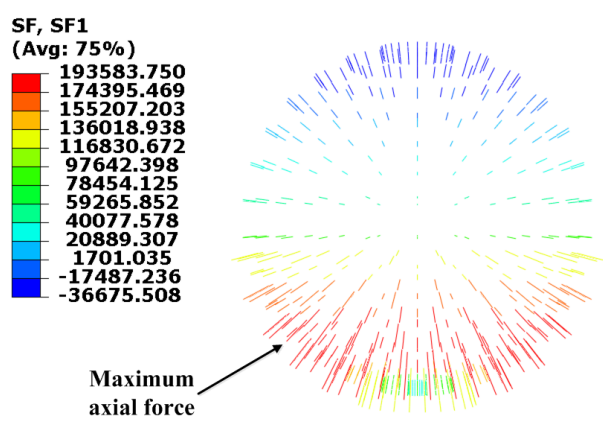

(c)

Fig. 2. (a) Mises stress on the acrylic ball/MPa, (b) Mises stress on the stainless steel latticed shell/MPa, (c) Axial force of braces/N, (d) Structural to 8.6 MPa and the amplification compared to the stress without consideration of earthquake is only $1.6 \%$. The maximum Mises stress on the latticed shell reaches $87.1 \mathrm{MPa}$ and the corresponding amplification is equal to $4.4 \%$. The maximum force of braces reaches $199.2 \mathrm{KN}$ and increased by $2.9 \%$. The maximum structural deflection is equal to $38.6 \mathrm{~mm}$ and increased by $10.0 \%$. It indicates that the variation is not pronounced and the structure is secure and reliable under the earthquake action.

\subsection{Joint failure}

The weakness of this structural scheme is the connection of the acrylic and stainless steel, thus the influence of the joint failure on the bearing behavior is imperative to be analyzed. In the present paper, the failure of the joint with largest stress, the failure of the joints in the same latitude of the joint with largest stress, the failure of the joints in the same longitude on the lower hemisphere and the failure of some random joints are separately taken into consideration. The results are shown in Fig. 3 .

It is noticed that the failure of the joints in the same longitude on the lower hemisphere leads to the greatest increase of the

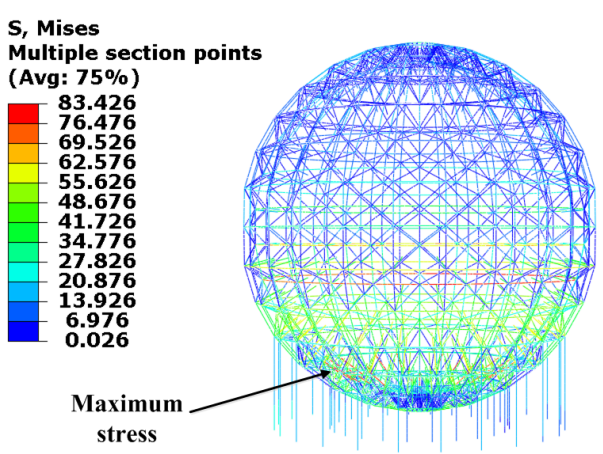

(b)

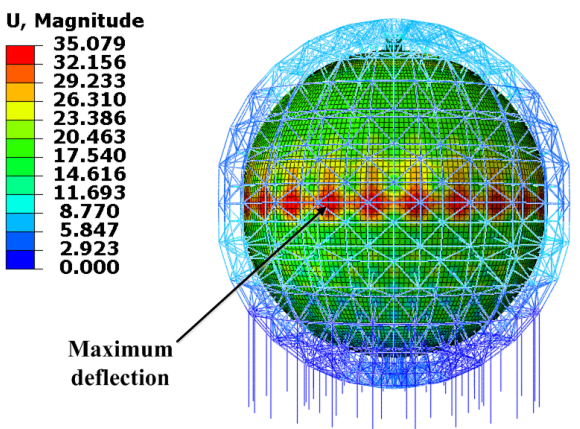

(d)

deflection $/ \mathrm{mm}$

Mises stress on the acrylic ball and the stress reaches $10.8 \mathrm{MPa}$ with an amplification of $27.1 \%$. However, if the partial load factor, 1.35 , is neglected, the real stress is equal to $8.0 \mathrm{MPa}$ and still lower than $10 \mathrm{MPa}$, nevertheless, the probability of this kind of failure is very low. The most possible condition is the failure of the joint with largest stress, in which the maximum Mises stress on the acrylic is equivalent to $9.1 \mathrm{MPa}$ and the amplification is equal to $7.1 \%$. Accordingly, this detector is relatively safe.

\section{Bearing capacity of the joint}

The acrylic ball is supported by stainless steel braces through the connecting joint in Fig. 1.b). However the structural stability is relative to the bearing capacity of the joint closely. Therefore the experimental and numerical researches on the mechanical behavior of the joint are necessary. It is known from Fig. 2(c) that the maximum axial force of braces is a tension about $193.6 \mathrm{KN}$ and the real force is about $140 \mathrm{KN}$, if the partial load factor is not taken into consideration. Consequently, $140 \mathrm{KN}$ is taken as the design load of the joint. Compared with stainless steel material, the acrylic material is weaker due to its 
Tab. 3. FE results under all liquid-level differences

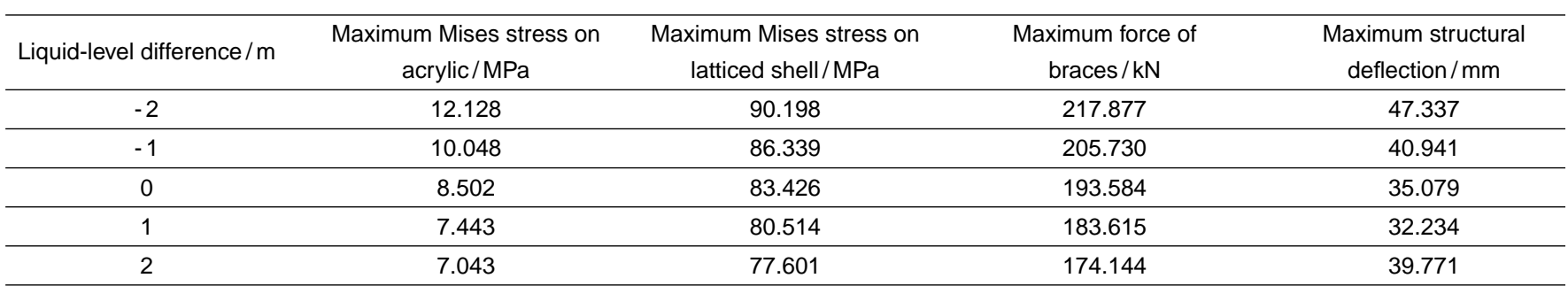

Tab. 4. Structural response under earthquake action

\begin{tabular}{cccc}
\hline Item & $\begin{array}{c}\text { Maximum Mises stress on } \\
\text { acrylic/MPa }\end{array}$ & $\begin{array}{c}\text { Maximum Mises stress on } \\
\text { latticed shell/MPa }\end{array}$ & $\begin{array}{c}\text { Maximum force of } \\
\text { braces } / \mathrm{kN}\end{array}$ \\
\hline Earthquake & 8.643 & 87.112 & 199.191 \\
\hline Amplification & $1.6 \%$ & $4.4 \%$ & $2.9 \%$ \\
\hline
\end{tabular}

lower yield strength. Thus the stress level on the acrylic is of great concern.

\subsection{Test procedure}

The test purpose is to investigate the ultimate load-bearing capacity, the stress level on the acrylic under the design load and the macroscopic response under long-term loading of the joint for the JUNO central detector.

\subsubsection{Specimens and measure points}

The joint specimens include three parts: main acrylic, patched acrylic, stainless steel fastener. The size of the main acrylic is $1800 \times 1800 \mathrm{~mm}$ and thickness $120 \mathrm{~mm}$. The size of the patched acrylic is shown in Fig. 4. Three non-identical specimens are designed, as presented in Fig.5(a)-(c). In tests, the main acrylic is restrained by a fixing device and the width of the contacting area is equal to $250 \mathrm{~mm}$, as shown in Fig. 5(d).

The type of the fastener, processing technology, temperature and illumination conditions are different for these specimens, leading to the discrepancies of initial imperfections, as depicted in Table 5. Specimen JD1 exhibits a lot of bubbles, since the fastener and patched acrylic are polymerized together and they show a great expanding discrepancy in the process of heating and cooling due to the different linear expansion coefficients. However, the patched acrylic and fastener are not polymerized together and a rubber blanket is utilized in JD3, whilst the requirements of temperature and illumination conditions are satisfied. Accordingly, the specimen JD3 is nearly not affected by the initial imperfection.

Strain rosettes are mainly distributed in three areas: the upper surface of the patched acrylic (represented by A), the upper surface of the main acrylic (represented by B) and the lower surface of the main acrylic (represented by $\mathrm{C}$ ). As numerous strain rosettes are utilised, only those with largest value are given, as presented in Fig. 6.a)-(c). A8-2 refers to the measure point A8 on the upper surface of the patched acrylic in the JD2 test and others can also be obtained by this way. All the displacement meters (represented by $\mathrm{W}$ ) in these three tests are provided, as presented in Fig. 6.(d)-(f). In the JD1 test, W1-1 and W3-1 measure the relatively vertical displacements between the fastener and main acrylic, whereas W2-1 and W4-1 measure those between the patched acrylic and main acrylic. In the JD2 test, all the displacement meters measure the relatively vertical displacements between the patched acrylic and main acrylic. In the JD3 test, W1-3 and W3-3 measure the relatively vertical displacements between the patched acrylic and main acrylic, while W2-3 and W4-3 measure those between the fastener and patched acrylic.

\subsubsection{Loading apparatus and method}

Due to the influence of gravity, when the force of the jack is applied to $155 \mathrm{KN}$, the actual load on specimens reaches the design value, $140 \mathrm{KN}$. In consideration of the misalignment in practical installation, loads applied on JD1 and JD2 are sideling with an angle of $5^{\circ}$, as depicted in Fig. 7(a), while the force on JD3 is vertically upward since the purpose of this test is to investigate the ultimate bearing capacity of this joint without consideration of the installation error, as presented in Fig. 7. (b). After $155 \mathrm{KN}$, a 10-day sustained loading test is carried out on the JD1 to study its bearing behavior under long-term loading. In this process, the load is totally provided by two lead screws.

The loading method consists of four steps, among which the sustained loading step is only for the JD1:

- Pre-loading. The load is applied with jack to $20 \mathrm{KN}$. If the displacement is pronounced, the setup will be adjusted to ensure the perfect contact of the specimen and fixing device. Then, the jack is unloaded.

- Step loading. The load is applied to $15 \mathrm{KN}$ at first and subsequently increases $20 \mathrm{KN}$ in each step until $155 \mathrm{KN}$. Meanwhile, the stress and displacement values will be measured.

- Sustained loading. Since the jack is unable to provide a longterm load, lead screws take the place of jack in this step. The load of the jack is firstly freed and then readjusted to a certain value. High-strength nuts on one side of lead screws are tight- 


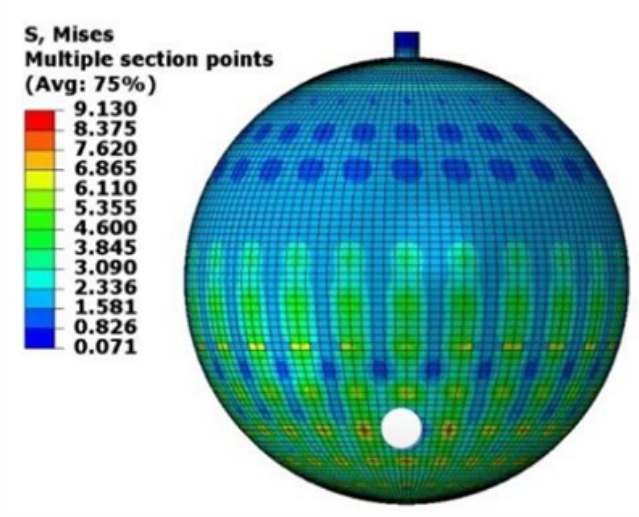

(a)

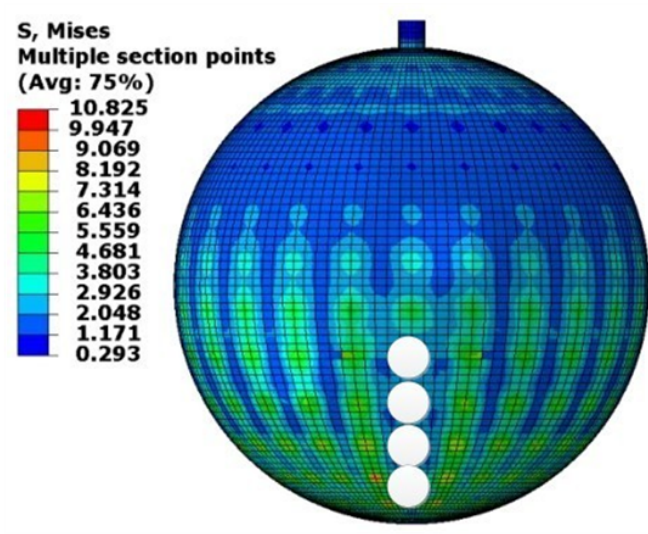

(c)

Fig. 3. (a) Failure of the joint with largest stress, (b) failure of the joints in the same latitude of the joint with largest stress, (c) failure of the joints in the

ened and the load of the jack is released slowly at the same time until the jack is entirely free.

- Failure loading. The load is applied using the jack until the failure of the specimen and the ultimate bearing capacity can be determined.

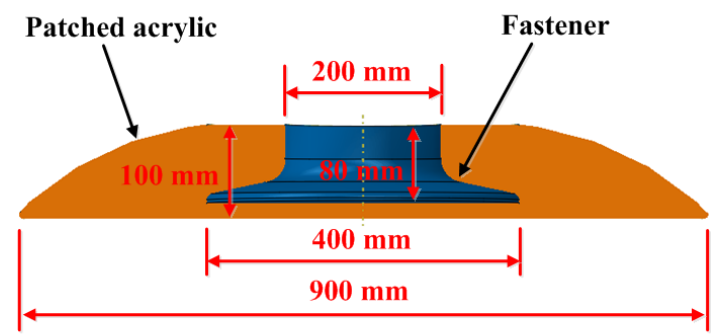

Fig. 4. Schematic diagram of the patched acrylic

\subsection{Test phenomenon and result}

\subsubsection{Test phenomenon and failure state}

There is no apparent phenomenon in the pre-loading and step loading stages in the JD1 test. However an initiation of a disengaged layer which locates at the edge of the stainless steel fastener is remarkable on 1-2 days in the sustained loading procedure, as shown in Fig. 8(a). The disengaged layer develops

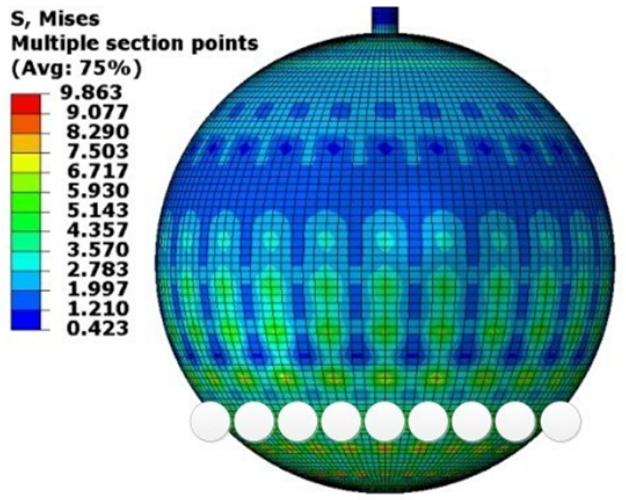

(b)

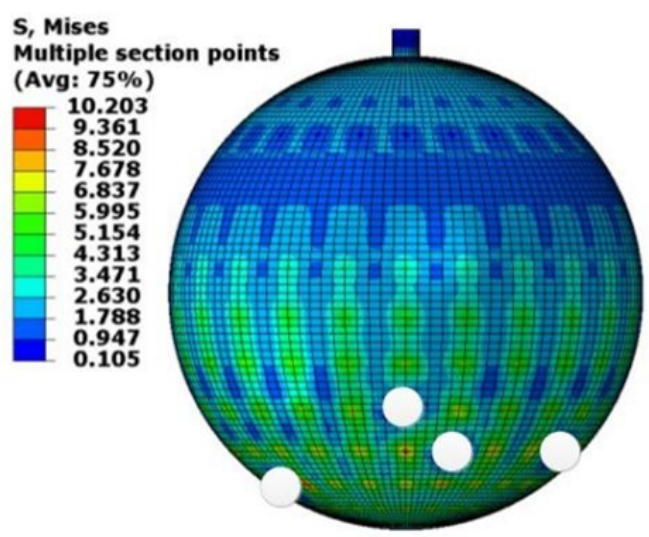

(d)

same longitude on the lower hemisphere, (d) failure of some random joints

along circular direction and finally to the two-thirds of the circle on 3-5 days. Afterwards bubbles gradually arise at the edge of the patched acrylic on 6-10 days, as depicted in Fig. 8(b). In the process of the failure loading, an obvious sound is made when the load reaches $240 \mathrm{KN}$ and bubbles continuously develop. At $288 \mathrm{KN}$, the crack propagates from the edge of the patched acrylic to the main acrylic, resulting in the rupture of the specimen JD1, as shown in Fig. 8.(c).

There is no apparent phenomenon in the pre-loading and step loading stages in the JD2 test. However, a tiny sound is made under $195 \mathrm{KN}$ in the process of the failure loading and the specimen fails at $325 \mathrm{KN}$ accompanying with a huge sound. The crack grows from the patched acrylic and develops to the main acrylic, as shown in Fig. 8(d).

No pronounced phenomenon appears in the pre-loading and step loading stages in JD3 test as well. When the load of the jack reaches $320 \mathrm{KN}$, a tiny sound is made. Finally, the specimen fails at $513 \mathrm{KN}$ accompanying with a huge sound and the separation of a large block of acrylic from the patched acrylic. Cracks symmetrically distribute along four directions, as shown in Fig. 8(e).

\subsubsection{Result curves}

For the sake of brevity, only a few parts of measuring result curves are presented in Fig. 9 


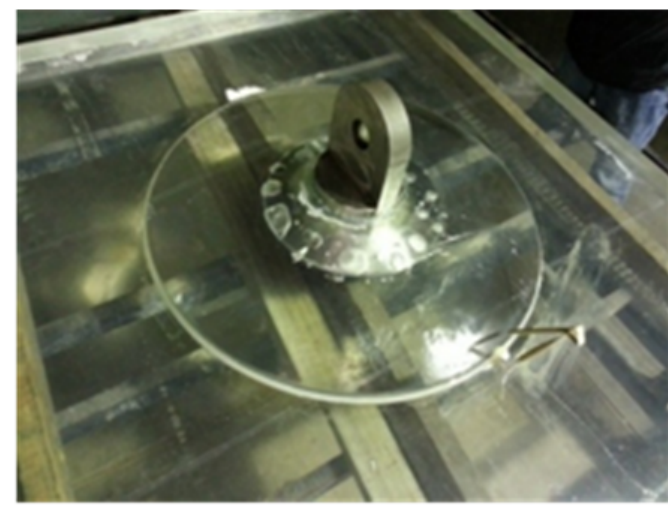

(a)

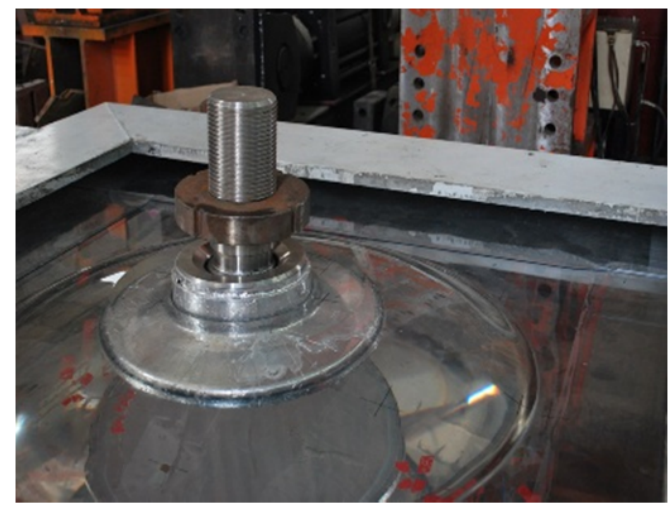

(c)

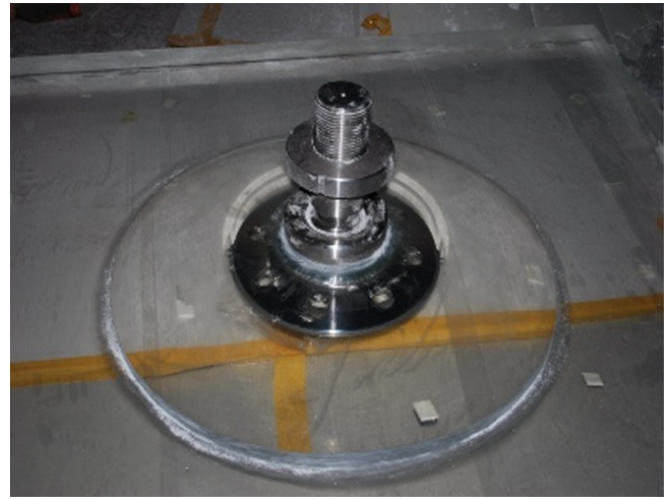

(b)

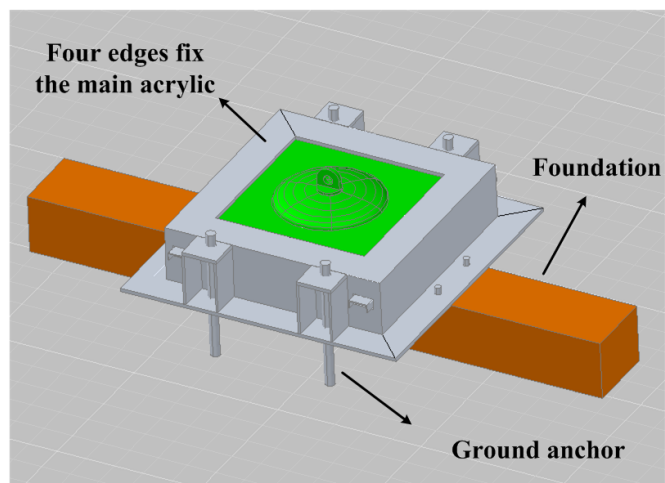

(d)

Fig. 5. Specimens and fixing device. (a) JD1, (b) JD2, (c) JD3, (d) fixing device.

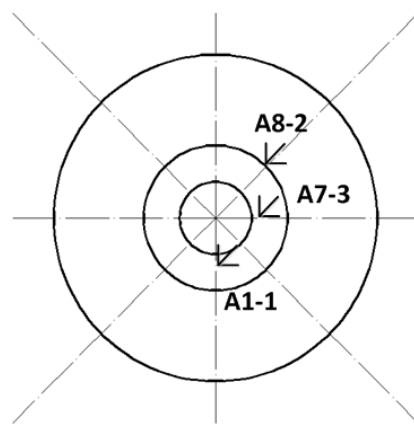

(a)

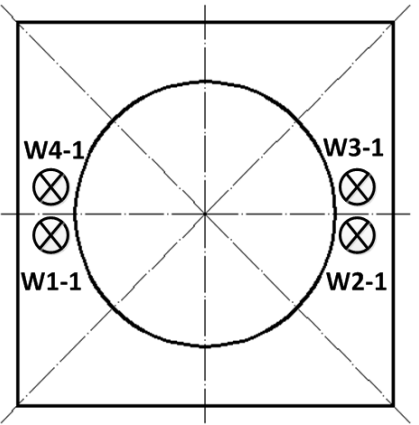

(d)

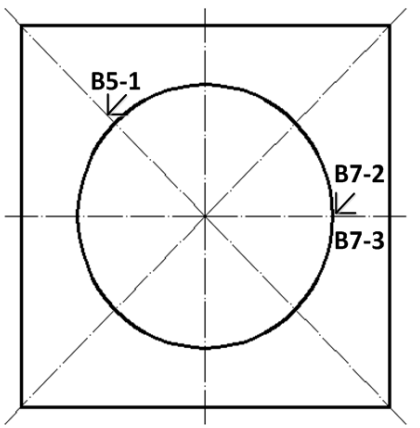

(b)

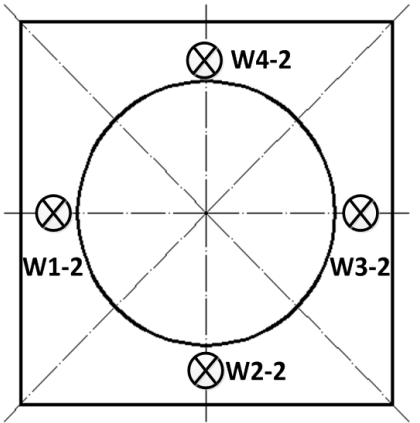

(e)

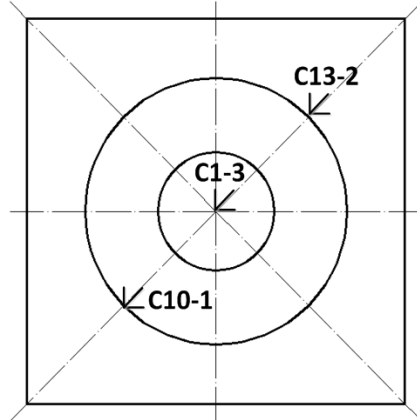

(c)

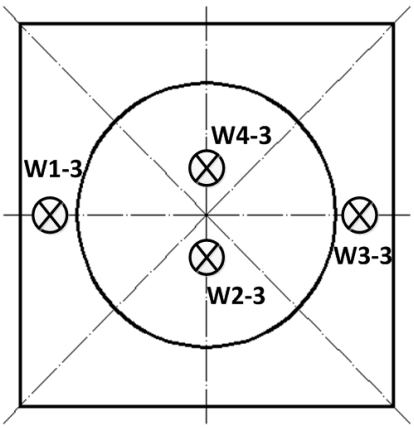

(f)
Fig. 6. Layout of measure points. (a) Strain rosettes on the upper surface of the patched acrylic, (b) strain rosettes on the upper surface of the main acrylic, (c) strain rosettes on the lower surface of the main acrylic, (d) displacement meters on JD1, (e) displacement meters on JD2, (f) displacement meters on JD3. 
Tab. 5. Specimen description

\begin{tabular}{|c|c|c|c|c|c|}
\hline number & Fastener type & $\begin{array}{l}\text { Hole condition on } \\
\text { fastener }\end{array}$ & Processing method & $\begin{array}{c}\text { Temperature and } \\
\text { illumination condition }\end{array}$ & Specimen description \\
\hline JD1 & Pin roll & No hole & $\begin{array}{l}\text { Fastener and patched } \\
\text { acrylic are } \\
\text { polymerized together }\end{array}$ & Not satisfied & $\begin{array}{c}\text { Defective, lots of } \\
\text { bubbles }\end{array}$ \\
\hline JD2 & Spherical hinge & $\begin{array}{l}8 \text { holes arranged } \\
\text { symmetrically }\end{array}$ & $\begin{array}{l}\text { Fastener and patched } \\
\text { acrylic are } \\
\text { polymerized together }\end{array}$ & Satisfied & $\begin{array}{c}\text { Defective, a few of } \\
\text { bubbles }\end{array}$ \\
\hline JD3 & Spherical hinge & No hole & $\begin{array}{l}\text { A rubber blanket } \\
\text { surrounds fastener }\end{array}$ & Satisfied & $\begin{array}{c}\text { Perfect, no apparent } \\
\text { bubbles }\end{array}$ \\
\hline
\end{tabular}

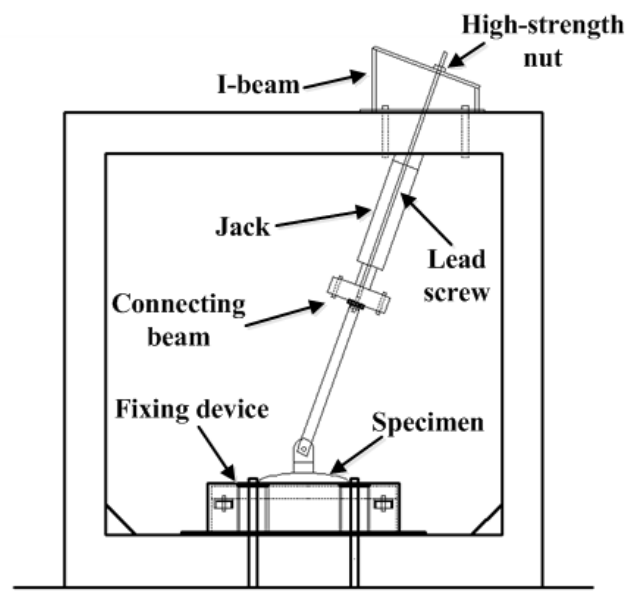

(a)

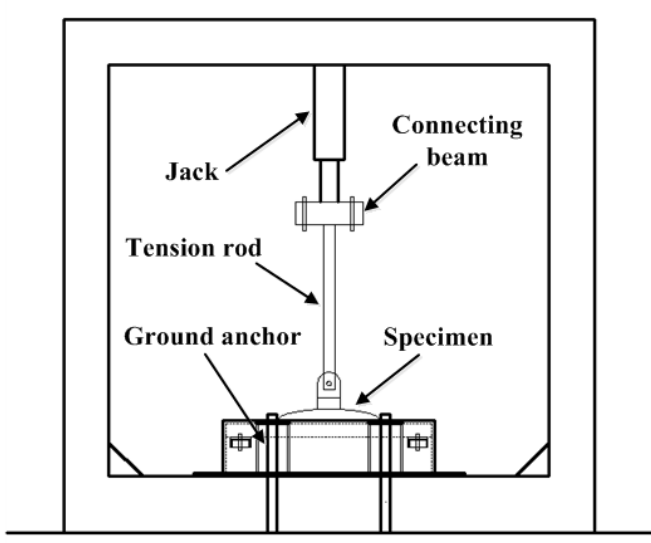

(b)

Fig. 7. Loading apparatus. (a) Loading schematic diagram of JD1 and JD2, (b) loading schematic diagram of JD3.

In Fig. 9 (a)-(b), the displacement and Mises stress versus load curves of some classic measure points on the JD1 are given. The curves in step loading and failure loading are listed in the same figure for the convenience of comparison. In Fig. 9.c)-(d), the displacement and Mises stress versus load curves of some measure points on the JD2 and JD3 are presented.

\subsection{Discussion}

In the sustained loading step of the JD1 test, the disengaged layer and bubbles appear at the edge of fastener and patched acrylic respectively, which is mainly caused by polymerization defects. However, the acrylic itself does not fail under long-term loading. It is known from Fig. 9 a)-(b) that the initial displacements and Mises stress of measure points are not equal to zero at the beginning of the failure loading, demonstrating that the creep behavior of the acrylic in the sustained loading step is obvious.

Cracks on the JD3 grow from the patched acrylic and propagate along four directions uniformly. That is because the load on the JD3 is vertically upward and the processing technology of the JD3 is more perfect than others. It is also known from test results that ultimate bearing capacities of the JD1, JD2 and JD3 are equal to $288 \mathrm{KN}, 325 \mathrm{KN}$ and $513 \mathrm{KN}$, respectively, and the bearing capacity of this kind of joint is at least twice as large as the design load. However, the ultimate bearing capacity of the
JD3 is enhanced substantially based on the previous ones.

There are no obvious phenomena under the design load, $140 \mathrm{KN}$, in these tests, thus specimens are relatively safe in this condition. Fig. 9(c)-(d) shows that acrylics of JD2 and JD3 almost remain elastic until the failure. However, when acrylics are subjected to an external load, a great deal of crazing appears and continuously develops into cracks with the increase of the load. As long as the load increases to some certain value, sounds will be made as a result of the crack extension. Only if the crack is long enough, an unstable propagation will happen, resulting in the failure of specimens. Fig. 8 shows that the failure form of acrylics is the penetration of one or several cracks and different from ordinary glasses.

\subsection{Numerical analysis}

\subsubsection{FE model}

The aim in carrying out the FE analysis is investigating the state of the joint under the design load, $140 \mathrm{KN}$. As the JD3 is less affected by the initial imperfection than the JD1 and JD2, only the FE model of the JD3 is introduced herein for the sake of brevity. The upper end of the fastener has little influence on the stress level of the acrylic and it can be simplified as the type in Fig. 10(a). Meanwhile, the load of $140 \mathrm{KN}$ is uniformly distributed on the upper surface. Since the joint kept elastic at $140 \mathrm{KN}$, the mechanical properties of the acrylic and stainless 


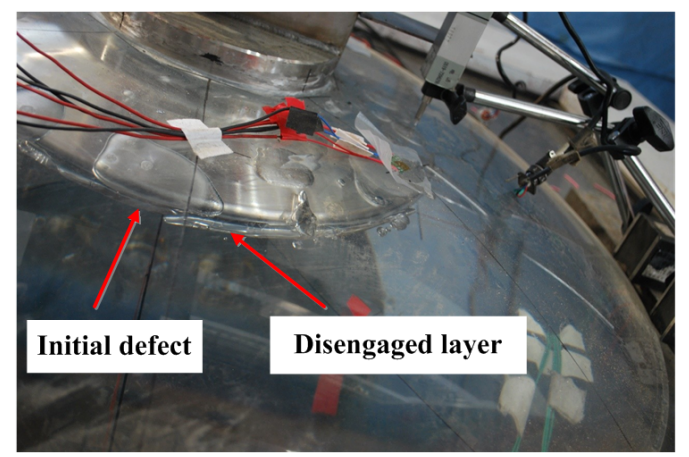

(a)

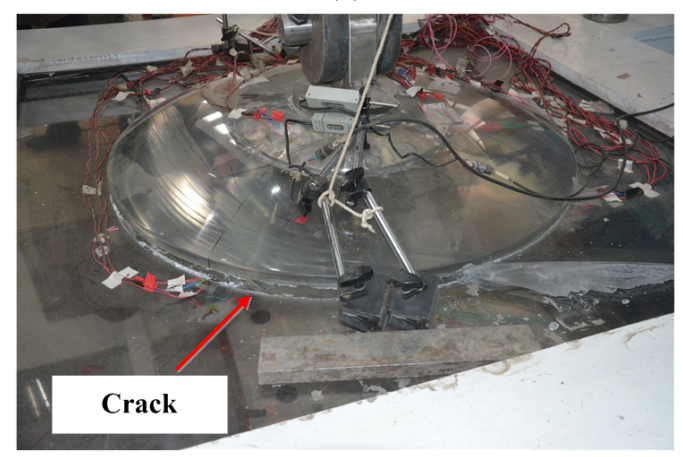

(c)

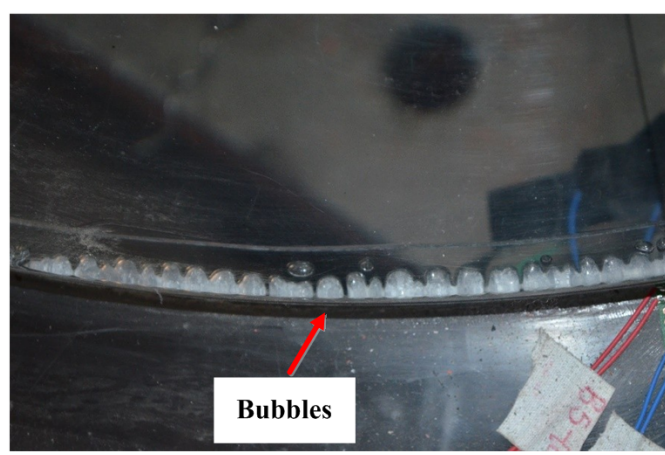

(b)

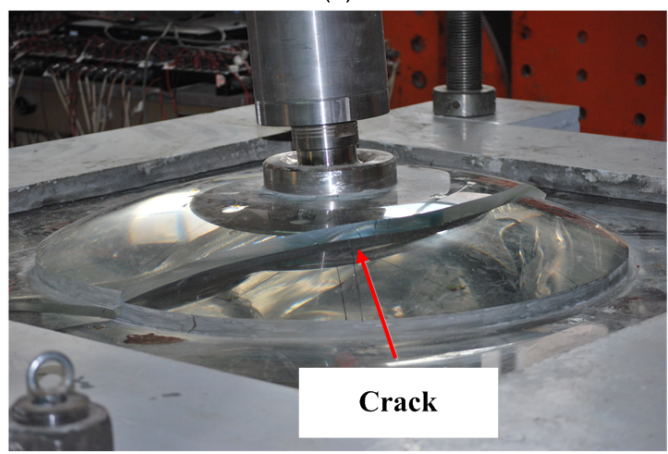

(d)

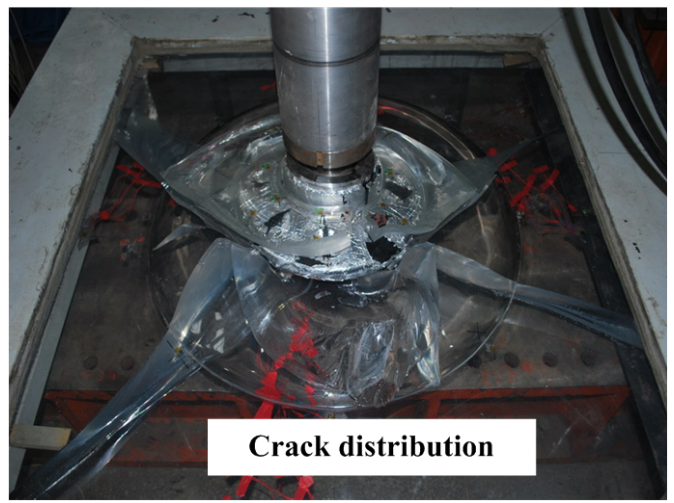

(e)

Fig. 8. Test phenomena. (a) Sustained loading for 1-2 days on JD1, (b) sustained loading for 6-10 days on JD1, (c) failure state of JD1, (d) failure state of

steel can be taken according to Table 2 The rubber is a kind of hyper-elastic material, but can be simplified as the elastic material under small deformation. The elastic modulus of the rubber is set to be 4.7 MPa and Poisson's ratio 0.5.

In the FE model, the solid element C3D8R is adopted for all parts. C3D8R is the 8-node linear brick element with reduced integration. The element number is 13185 and the node number is 17487 . As the main acrylic and patched acrylic are connected as a whole part by the bulk polymerization and the relative displacement between these two parts will lead to the failure of the joint specimen, the connection between them can be defined using the "Tie" command in the "Constraint Manager", as presented in Fig. 10.a). However, the relative sliding between the patched acrylic, rubber and fastener is possible, thus the connection between them is simulated by the "surface-to-surface" contact in the "Interaction Manager", as shown in Fig. 10.b).
JD2, (e) failure state of JD3.

\subsubsection{Comparison between FE and test results}

In order to obtain the values in tests corresponding to the FE results, test values under $15 \mathrm{KN}$ are subtracted from those under $155 \mathrm{KN}$. The comparison between test and FE results of JD1, JD2 and JD3 is shown in Table 6 Only the maximum displacements in tests are given.

It is noticed that the relative displacements in these three joint tests are all very small and less than $2 \mathrm{~mm}$. Therefore the displacement is not the controlling factor. The maximum Mises stress on the acrylic does not exceed $10 \mathrm{MPa}$, which satisfies the requirement of the JUNO central detector.

The JD3 is processed with a perfect polymerization so that the elasticity modulus of the patched acrylic reaches the standard, thus stresses on the patched acrylic of the JD3 are significantly higher than those on the patched acrylics of the JD1 and JD2. In general, the FE results of the JD3 are well consistent with the experimental counterparts. However, the numerical results of 


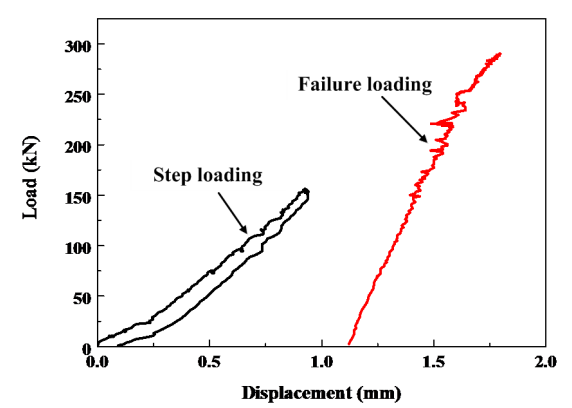

(a)

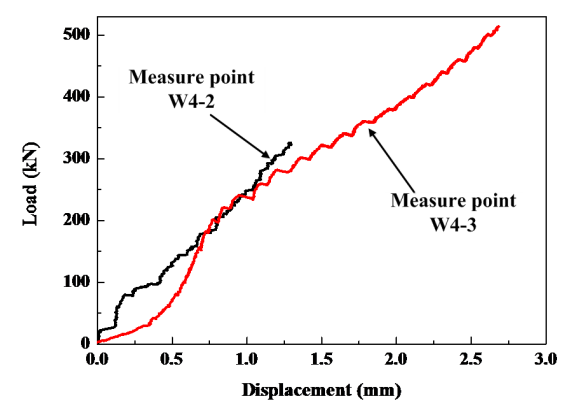

(c)

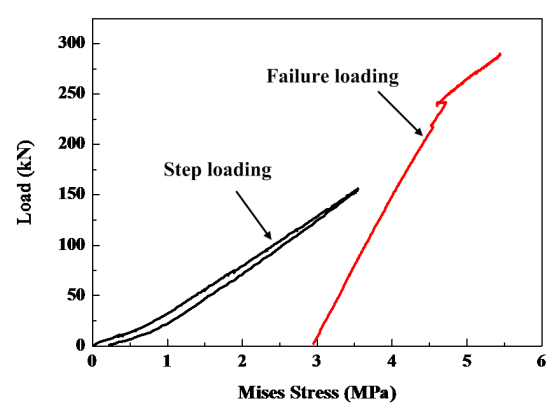

(b)

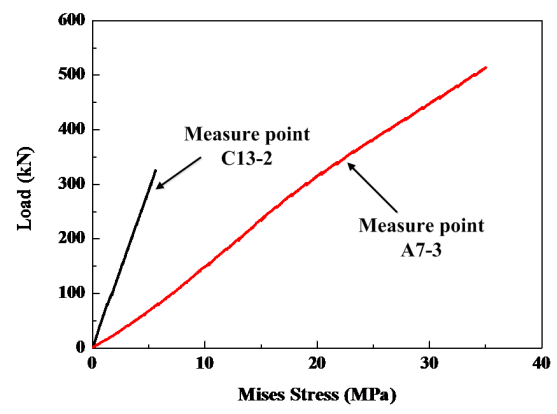

(d)
Fig. 9. Result curves. (a) Load-displacement curves of measure point W31 on JD1, (b) load-stress curves of measure point B5-1 on JD1, (c) load- displacement curves of measure points on JD2 and JD3, (d) load-stress curves of measure points on JD2 and JD3.

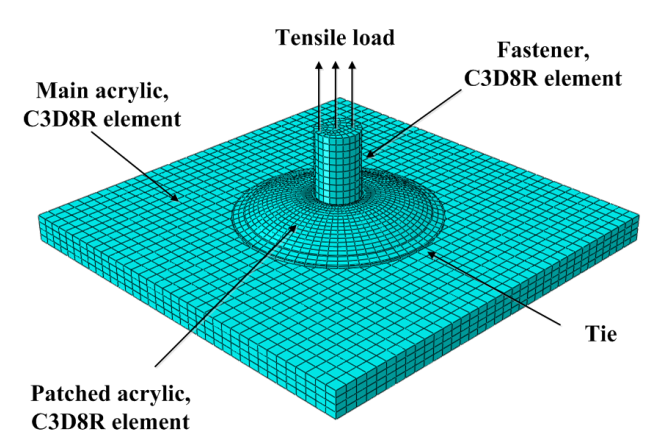

(a)

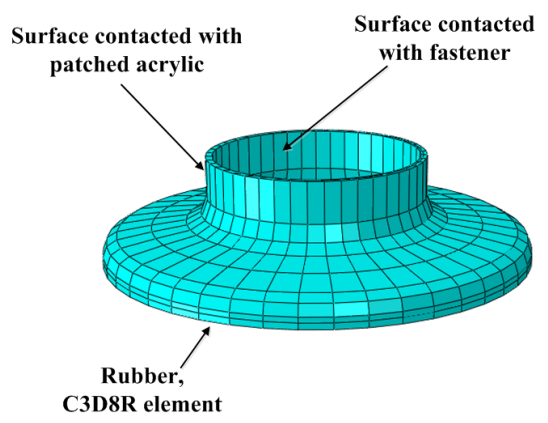

(b)

Fig. 10. Mesh partition. (a) Whole joint, (b) rubber.

Tab. 6. Comparison between numerical and experimental results

\begin{tabular}{|c|c|c|c|c|}
\hline Specimen & Comparative item & Measure point & Test result & FE result \\
\hline \multirow{4}{*}{ JD1 } & \multirow{3}{*}{ Mises stress (MPa } & A1-1 & 4.722 & 5.534 \\
\hline & & B5-1 & 3.954 & 1.476 \\
\hline & & C10-1 & 2.647 & 1.713 \\
\hline & Displacement & W1-1 & 0.814 & 0.985 \\
\hline \multirow{4}{*}{ JD2 } & \multirow{3}{*}{ Mises stress (MPa } & A8-2 & 2.525 & 2.909 \\
\hline & & B7-2 & 2.593 & 1.703 \\
\hline & & C13-2 & 2.461 & 2.580 \\
\hline & Displacement & W2-2 & 0.625 & 1.032 \\
\hline \multirow{4}{*}{ JD3 } & \multirow{3}{*}{ Mises stress (MPa } & A7-3 & 8.467 & 8.392 \\
\hline & & B7-3 & 3.479 & 2.963 \\
\hline & & C1-3 & 3.262 & 3.093 \\
\hline & Displacement & W4-3 & 0.512 & 0.630 \\
\hline
\end{tabular}


the JD1 and JD2 have a certain discrepancy with the experimental results. That is because the initial defects have pronounced effects on these specimens, which is hardly stimulated in the FE model.

\section{Conclusions}

The structural scheme of an acrylic ball supported by a double-layer stainless steel latticed shell is proposed for the JUNO central detector, and afterwards the FE simulation of the structure is conducted in the ABAQUS software. The bearing capacity of the detector is investigated in consideration of the variation of the liquid level, earthquake action and joint failure. Furthermore, the bearing behavior of the connecting joint of the acrylic and stainless steel is intensively studied by the experimental and numerical methods. The conclusions can be drawn as follows:

- In this scheme, the maximum Mises stress on the acrylic ball is equal to $8.5 \mathrm{MPa}$, less than $10 \mathrm{MPa}$. The maximum Mises stress on the latticed shell is equal to $83.4 \mathrm{MPa}$, significantly lower than the yield strength. The maximum axial force of braces reaches $193.6 \mathrm{KN}$ and it is the tensile force. The maximum structural deflection is about $35.1 \mathrm{~mm}$, approximately equal to $1 / 1014$ of the span. All these results satisfy the requirement of the JUNO central detector.

- The elevation of the liquid level inside the acrylic ball is advantageous for the structure. When the liquid level difference inside and outside is equal to $2 \mathrm{~m}$, the maximum Mises stress on the acrylic is decreased by $17.2 \%$ compared with the result at $0 \mathrm{~m}$. The earthquake has little influence on the structure, which merely leads to the stress amplification of $1.6 \%$ on the acrylic and $4.4 \%$ on the latticed shell. The most possible failure mode in the whole structure is the failure of the joint with largest stress, which results in the maximum Mises stress on the acrylic reaching 9.1 MPa. However, it is still lower than $10 \mathrm{MPa}$. In sum, the structure is secure and reliable.

- The ultimate bearing capacities of three joint specimens designed in the present paper are equal to $288 \mathrm{KN}, 325 \mathrm{KN}$, $513 \mathrm{KN}$, respectively, and the bearing capacity of this kind of joint is at least twice as large as the design load. It is known from test and FE results that the maximum stress on the acrylic of the joint is lower than $10 \mathrm{MPa}$, which satisfies the using requirement.

- In JD2 and JD3 tests, the acrylic keep elastic before the failure, while the acrylic exhibits the creep response under longterm loading in the JD1 test. In the failure loading step, when the external load increases, the crazing and defects generally develop into cracks, which will propagate unstably at last and lead to the rupture of specimens. It is noticed that although the failure of the acrylic is brittle, it will not present the fragment state and is different from ordinary glasses. Thereby, the acrylic is less dangerous to residents and suitable to be utilized in building structures.
- In the processing of the joint, the common polymerization of acrylic and stainless steel should be avoided, because the discrepancy of linear expansion coefficients between these two materials will trigger lots of bubbles inside the acrylic. Meanwhile, requirements of temperature and illumination conditions should be satisfied as well.

\section{Acknowledgement}

The project presented in this article is supported by the Tsinghua University Initiative Scientific Research Program, (No 20131089288), and the Strategic Priority Research Program of the Chinese Academy of Sciences (NO XDA10010200).

\section{References}

1 Fukuda S, Fukuda Y, Hayakawa T, The Super-Kamiokande detector, Nuclear Instruments and Methods in Physics Research Section A: Accelerators, Spectrometers, Detectors and Associated Equipment, 501(2-3), (2003), 418462, DOI 10.1016/S0168-9002(03)00425-X

2 Aharmim B, Ahmed SN, Anthony AE, Combined analysis of all three phases of solar neutrino data from the sudbury neutrino observatory, Physical Review C, 88(2), (2013), 025501, DOI 10.1103/PhysRevC.88.025501

3 Benziger J, Cadonati L, Calaprice F, The nylon scintillator containment vessels for the borexino solar neutrino experiment, Nuclear Instruments and Methods in Physics Research Section A: Accelerators, Spectrometers, Detectors and Associated Equipment, 582(2), (2007), 509-534, DOI 10.1142/S0217751X14420044

4 Kouchner A, Recent results from the ANTARES neutrino telescope, Brazilian Journal of Physics, 44(5), (2014), 550-559, DOI 10.1007/s13538-0140229-3

5 Taboada I, Neutrino astrophysics with IceCube, Nuclear Instruments and Methods in Physics Research Section A: Accelerators, Spectrometers, Detectors and Associated Equipment, 742, (2014), 71-76, DOI 10.1016/j.nima.2013.11.093

6 Stachiw JD, Handbook of Acrylics for Submersibles Hyperbaric Chambers and Aquaria, Best Publishing Company; Florida, 2003.

7 Wu HY, Ma G, Xia YM, Experimental study of tensile properties of PMMA at intermediate strain rate, Materials Letters, 58(29), (2004), 3681-3685, DOI 10.1016/j.matlet.2004.07.022

8 Richeton J, Ahzi S, Vecchio KS, Jiang FC, Adharapurapu RR, Influence of temperature and strain rate on the mechanical behavior of three amorphous polymers: Characterization and modeling of the compressive yield stress, International Journal of Solids and Structures, 43(7-8), (2006), 2318-2335, DOI 10.1016/j.ijsolstr.2005.06.040

9 Richeton J, Ahzi S, Vecchio KS, Jiang FC, Makradi A, Modeling and validation of the large deformation inelastic response of amorphous polymers over a wide range of temperatures and strain rates, International Journal of Solids and structures, 44(24), (2007), 7938-7954, DOI 10.1016/j.ijsolstr.2007.05.018

10 Richeton J, Ahzi S, Daridon L, Thermodynamic investigation of yieldstress models for amorphous polymers, Philosophical Magazine, 87(24), (2007), 3629-3643, DOI DOI 10.1080/14786430701381162

11 Chen W, Lu F, Cheng M, Tension and compression tests of two polymers under quasistatic and dynamic loading, Polymer Testing, 21(2), (2002), 113121, DOI 10.1016/S0142-9418(01)00055-1

12 Palm G, Dupaix RB, Gastro J, Large strain mechanical behavior of poly(methyl methacrylate) (PMMA) near the glass transition temperature, Journal of Engineering Materials and Technology- Transactions of the ASME, 128(4), (2006), 559-563, DOI 10.1115/1.2345447

13 Hasan EH, El-Sayed AA, Ibrahim MM, Dynamic crack propagation for 
PMMA under different annealing temperatures, Polymer-Plastics Technology and Engineering, 42(4), (2003), 569-580, DOI 10.1081/PPT-120023096

14 Mekawey FML, Hasan EH, Barakat MA, Study of crack propagation in PMMA using ultrasonic technique, Polymer-plastic Technology and Engineering, 46(2), (2007), 151-156, DOI 10.1080/03602550601152978

15 Wang YQ, Yuan HX, Shi YJ, Zou Y, Bearing capacity of non-linear metallic spiders used in point supported glass facades, International Journal of Steel Structures, 12(2), (2012), 191-204, DOI 10.1007/s13296-012-2004-Z

16 Yang L, Wang YQ, Gao B, Shi YJ, Yuan HX, Two calculation methods for buckling reduction factors of stainless steel welded I-section beams, ThinWalled Structures, 83, (2014), 128-136, DOI 10.1016/j.tws.2014.01.012

17 Wang YQ, Yang L, Gao B, Shi YJ, Yuan HX, Experimental study of lateral-torsional buckling behavior of stainless steel welded I-section beams, International Journal of Steel Structures, 14(2), (2014), 411-420, DOI 10.1007/s13296-014-2019-8

18 Yang L, Wang YQ, Guan J, Zhang Y, Shi YJ, Bearing strength of stainless steel bolted connections, Advances in Structures Engineering, 18(7), (2015), 1051-1062.

19 Wang YQ, Chang T, Shi YJ, Yuan HX, Yang L, Experimental study on the constitutive relation of austenitic stainless steel S31608 under monotonic and cyclic loading, Thin-Walled Structures, 83, (2014), 19-27, DOI 10.1016/j.tws.2014.01.028

20 Fan SG, Liu F, Zheng BF, Shu GP, Tao YL, Experimental study on bearing capacity of stainless steel lipped $C$ section stub columns, Thin-Walled Structures, 83, (2014), 70-84, DOI 10.1016/j.tws.2014.02.002

21 Fan SG, Tao YL, Zheng BF, Liu F, Capacity of stainless steel lipped $C$ section stub column under axial compression, Journal of Construction steel research, 103, (2014), 251-263, DOI 10.1016/j.jcsr.2014.09.013

22 Salih EL, Gardner L, Nethercot DA, Bearing failure in stainless steel bolted connections, Engineering Structures, 33(2), (2011), 549-562, DOI 10.1016/j.engstruct.2010.11.013

23 Nethercot DA, Salih EL, Gardner L, Behaviour and Design of Stainless Steel Bolted Connections, Advances in Structures Engineering, 14(4), (2011), 647-658.

24 Salih EL, Gardner L, Nethercot DA, Numerical study of stainless steel gusset plate connections, Engineering Structures, 49, (2013), 448-464, DOI 10.1016/j.engstruct.2012.11.032

25 Belytschko T, Wong BL, Chiang HY, Advances in one-point quadrature shell elements, Computer Methods in Applied Mechanics and Engineering, 96(1), (1992), 93-107.

26 Nascimbene R, Towards Non - Standard Numerical Modeling of ThinShell Structures: Geometrically Linear Formulation, International Journal for Computational Methods in Engineering Science and Mechanics, 15(2), (2014), 126-141, DOI 10.1080/15502287.2013.874058

27 EN 1993-1-4:2005, Eurocode 3: Design of steel structures - Part 1-4: General rules-supplementary rules for stainless steel, European Committee for Standardization (CEN), 2005.

28 Wang YQ, Zong L, Heng YK, Wang ZY, Zhou Y, Hou SJ, Qin ZH, Ma $\mathbf{X Y}$, Application of an acrylic vessel supported by a stainless steel truss for the JUNO central detector, Science China Technological Sciences, 57(12), (2014), 2523-2529, DOI 10.1007/s11431-014-5715-x

29 JGJ7-2010, Technical Specification for Space Frame Structures, China Architecture \& Building Press; Beijing, 2010.

30 GB50011-2010, Code for Seismic design of buildings, China Architecture \& Building Press; Beijing, 2010.

31 Yang Y, Chen JT, Xiao M, Analysis of Seismic Damage of Underground Powerhouse Structure of Hydropower Plants Based on Dynamic Contact Force Method, Shock and Vibration, 859648, (2014), DOI $10.1155 / 2014 / 859648$

32 Smerzini C, Avilés J, Sánchez-Sesma FJ, Paolucci R, Analytical solutions for the seismic response of underground structures under SH wave propagation, Conference on Seismic Engineering Conference, 2008-07-08, In: AIP Conference Proceedings; Univ Reggio, Calabria, 2010, pp. 647-683.

33 Kouretzis GP, Bouckovalasa GD, Gantes CJ, 3-D shell analysis of cylindrical underground structures under seismic shear $(S)$ wave action, Solid Dynamics and Earthquake Engineering, 26(10), (2006), 909-921, DOI 10.1016/j.solidyn.2006.02.002 